\title{
EFFECT OF PYRAMIDAL DOME GEOMETRY ON THE ACOUSTICAL CHARACTERISTICS IN A MOSQUE
}

\author{
Dg. H. Kassim ${ }^{1}$, A. Putra ${ }^{1 *}$, M.J.M. Nor ${ }^{2}$ and N.S. Muhammad ${ }^{1}$ \\ ${ }^{1}$ Centre for Advanced Research on Energy (CARE) \\ Universiti Teknikal Malaysia Melaka (UTeM) \\ Hang Tuah Jaya 76100, Durian Tunggal, Melaka, Malaysia \\ Email: azma.putra@utem.edu.my \\ Phone: +60 6-234 6873;Fax: +60 6-234 6884 \\ ${ }^{2}$ Department of Mechanical and Materials Engineering \\ Faculty of Engineering \& Built Environment \\ Universiti Kebangsaan Malaysia, 43600 UKM, Bangi Selangor, Malaysia
}

\begin{abstract}
As an important symbol in Islam, a mosque is built with architectural grandeur. Among the characteristics is its high ceiling and it is usually constructed with a typical spherical dome shape. Some mosques, however, are influenced by the local culture and the dome can be of a different shape, such as pyramidal, as found in mosques in Malacca, Malaysia. This paper presents an assessment of the internal acoustical characteristics of a mosque having a pyramidal dome. The study is conducted by means of computer simulation using CATT indoor acoustic software. Reverberation time and clarity are taken to evaluate the intelligibility of speech. The effect of the angle and height of the dome on the acoustical parameters is discussed. It is found that a pyramidal dome with a steeper angle contributes to poor acoustic clarity.
\end{abstract}

Keywords: Mosque; speech intelligibility; pyramidal dome; reverberation time.

\section{INTRODUCTION}

The mosque is inseparable from a Muslim community. It not only serves for ritual praying activity, but also has other social roles such as for preaching and public speaking. The latter activities require speech intelligibility and therefore good acoustic quality is important. Interest has been shown in the acoustic performance in mosques in the past 15 years, but has been mostly related to real-time acoustic measurement [1-3]. The studies then continue with computer simulation, which is a more attractive approach and is used for designing improvements to the acoustic quality [4-6]. The most recent study by Putra et al. [7] presents the possibility of applying micro-perforated absorbers to counter the low frequency problem in a local mosque. From previous studies, the dome is suspected of contributing to the poor intelligibility of speech in the mosque. The construction of a dome, however, is essential as one of the architectural characteristics of the mosque. The use of a dome is well-known since the Ottoman era. Despite having greatness in size and aesthetics, however, it repeatedly causes defects in the acoustical performance of a mosque [8], yet only a few research works are available on the effect of the dome on the acoustics in a mosque. Soegijanto [9] studied the effect of typical domes or roof shapes in mosques in Indonesia using computer simulation. From three different roof-ceiling shapes, the hall with a dome and pyramidal tier-roof 
has high potential for producing sound concentrations and echoes compared to a ceiling with a flat surface. Prodi and Marsilo [10] developed a scale model of a mosque to study the effect of the coupling between the volume of the dome and the remaining volume of the mosque on the reverberation time. The volume could be adjusted by raising or lowering the floor. From the measurement data, it was found that the dome ceiling can help to lower the reverberation time only with a reflective floor condition. Setiyowati [11] discussed the results of acoustic measurements of several local mosques and it was concluded that the dome shape has an important effect on the acoustics inside a mosque. The author proposed that various shapes should be considered possible, on the condition that it must be arranged well to avoid late reflections and focusing of sound problems.

This paper presents a study in more detail on the effect of a pyramidal dome on the acoustics of a mosque. This study was conducted as there is still a lack of research concerning the effect of the dome on acoustics in a mosque, and especially pyramidal domes which have long existed and are still applied as part of the architectural design. In Malaysia, this type of mosque is mostly found in the State of Malacca, where the architecture of the mosque, including the roof or dome, follows the traditional Malay house. Figure 1 shows the Sayyidina Abu Bakar Mosque, which has become an icon for the Universiti Teknikal Malaysia Melaka (UTeM) in Malacca, where the dome is pyramidal rather than the typical spherical shape. A simulation was conducted to calculate the reverberation time (RT) and the clarity (C50) as the main parameters that define the intelligibility of speech.

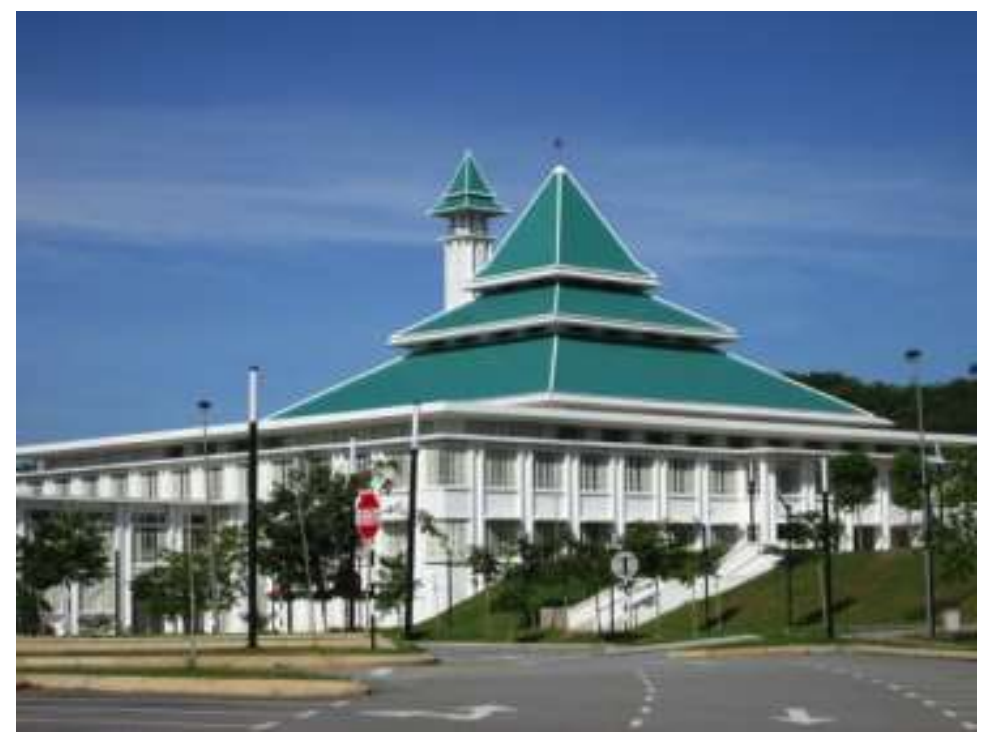

Figure 1. The Sayyidina Abu BakarUTeM with pyramidal dome.

\section{THE CATT MODEL}

The mosque's geometry details are modelled using CATT indoor acoustic software version 9. The absorption coefficient for the materials is selected from the software library. Omni-directional sound sources emitting white noise are used in the model and are located at a typical location inside the mosque, namely the mihrab. Receivers are located scattered across the floor at $0.5 \mathrm{~m}$ height, assuming that listeners are in a sitting 
position. Figure 2 shows an example of the CATT model of the mosque and its interior view.

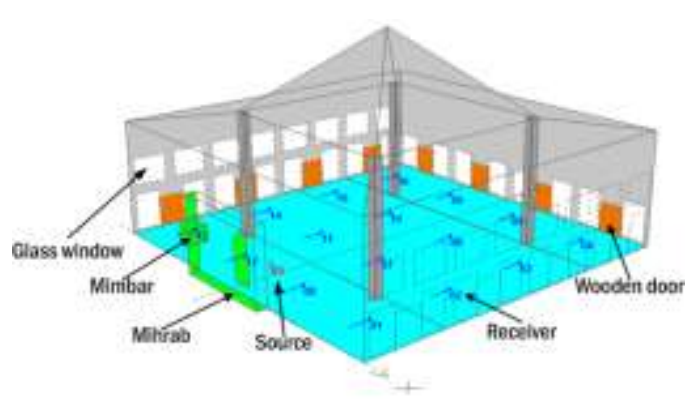

(a)

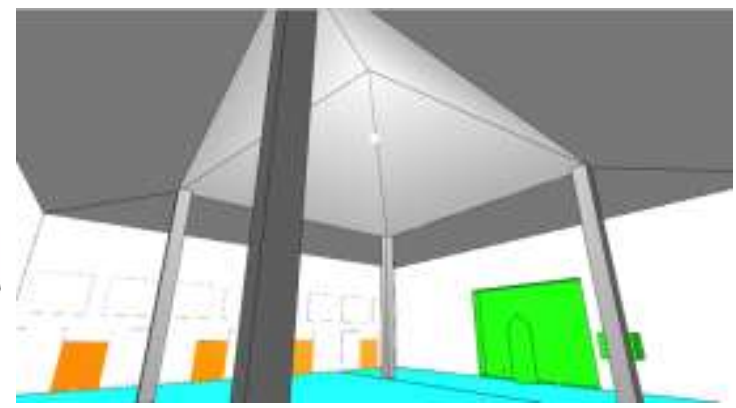

(b)

Figure 2.(a) 3D view of the CATT model; (b) interior view.

To investigate the effect of the pyramidal dome on the acoustical characteristics, three different inclined angles of pyramidal dome are modelled. Figure 3 shows the diagram of the mosque with pyramidal dome geometry, where $t$ is the dome height, $\alpha$ is the angle between the inclined surface and a horizontal surface and $w$ is the height of the wall. The angles are defined by the change of the dome height, thus giving different values of $\alpha$. The height of the wall $w$ is adjusted to maintain the total volume of the mosque. This is to avoid the effect of a change in volume on the acoustical parameters and to ensure that the analysis is based on the characteristics of the dome. Figure 4 shows the 2D CATT model of the mosque with three different pyramidal domes.

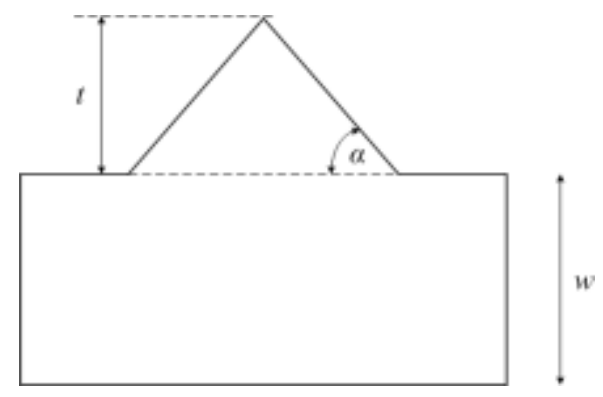

Figure 3.2D diagram of the mosque model with pyramidal dome.

(a)

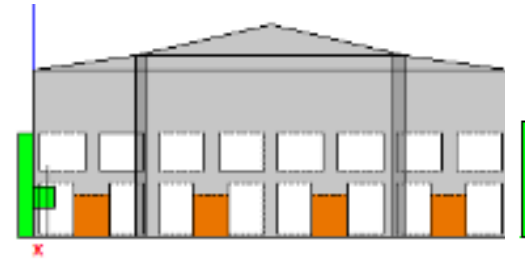

(b)

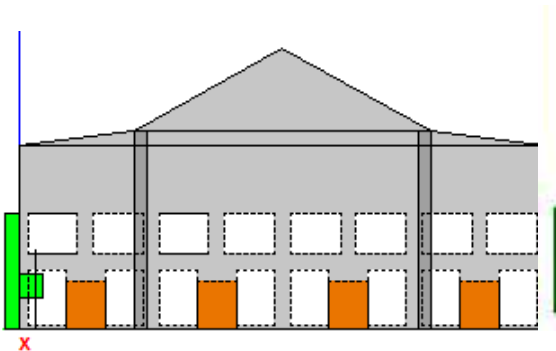

(c)

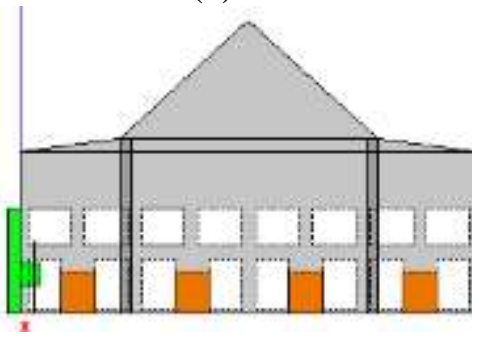

Figure 4. 2D CATT model of the mosque with different pyramidal dome configurations:(a) $\alpha=9^{\circ}$ (b) $\alpha=20^{\circ}$ and (c) $\alpha=31^{\circ}$. 


\section{RESULTS AND DISCUSSION}

The results presented here are for $500 \mathrm{~Hz}$, a frequency important in affecting the intelligibility of speech.

\section{Reverberation Time}

Reverberation time is a basic parameter used as an objective measurement of the acoustical characteristics in a mosque. It is defined as the time for the decrement of sound energy by $60 \mathrm{~dB}$ after the sound source is switched off. Researchers have proposed several 'acceptable' RT graphs based on the volume of a room and its function [12]. For example, a room designed for musical performance may have a higher RT than that intended for speech. Figure 5 shows the mapping of RT at the plane $0.5 \mathrm{~m}$ above the floor, together with its histogram for different dome heights and angles. Here, it is shown that most of the area experiences high RT, i.e. above $3 \mathrm{~s}$, except at the front area around the mihrab, where direct sound from the source is dominant. For the rest of the area, late reflections dominate and thus increase the RT. A slightly higher percentage of rays arrives at $3.2 \mathrm{~s}$ for $\alpha=31^{\circ}$. This is because more reflections occur inside the dome before the sound waves propagate into the main hall of the mosque.

(a)

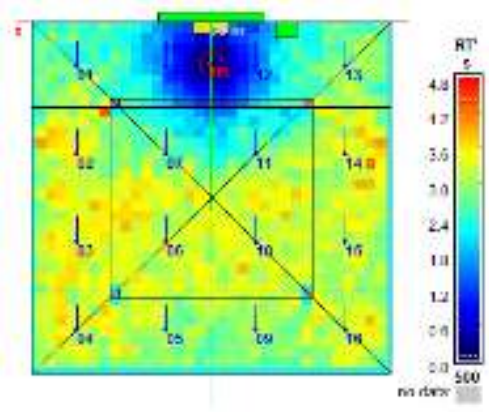

(b)

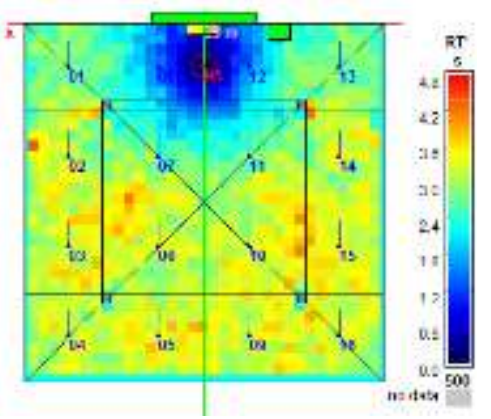

(c)

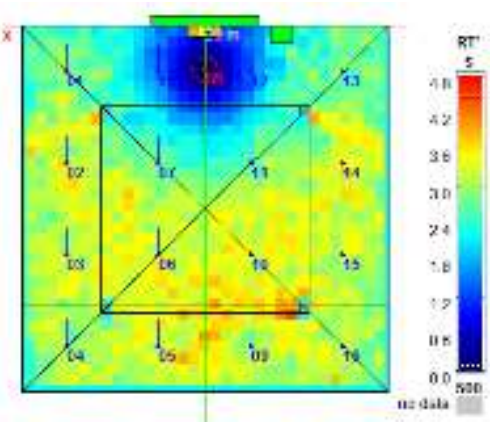

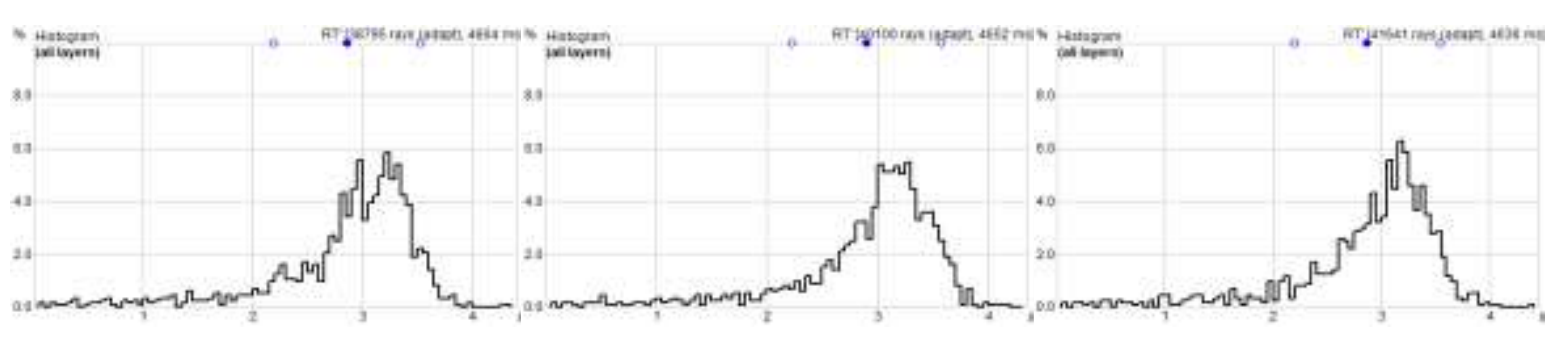

Figure 5. Mapping and histogram of reverberation time for:

(a) $\alpha=9^{\circ}$, (b) $\alpha=20^{\circ}$, and (c) $\alpha=31^{\circ}$.

\section{Clarity}

Clarity (C50) is often used to determine the intelligibility of speech [13], and is defined as the ratio of early to late arriving sound. Values in the range of -3 to $+9 \mathrm{~dB}$ are found to be suitable in a room designed for speech [14]. Figure 6 shows that around one third of the floor area (from the mihrab) has good C50 for all three conditions of the dome. 
The receivers in this area are still assisted by the direct sound received from the sound source in the mihrab. If the mosque is mostly occupied by one third of its volume, for example, during the prayer congregation, this condition is still practically acceptable. However, at the middle and the back area, including below the dome, C50 is poor and this becomes worse as the height of the dome is increased. The histogram in Figure 6 shows that the distribution trend of the clarity shifts to the left (negative values) with increasing dome angle. As the angle of the dome increases, more sound energy is trapped, causing more late reflections and so contributing to poor clarity of speech.

(a)

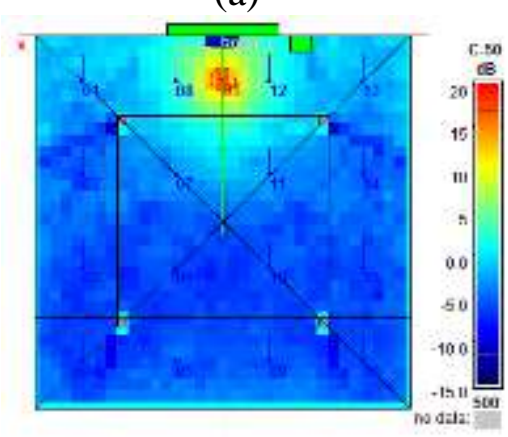

(b)

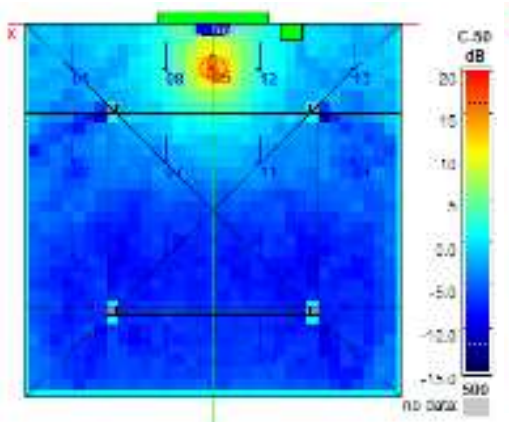

(c)

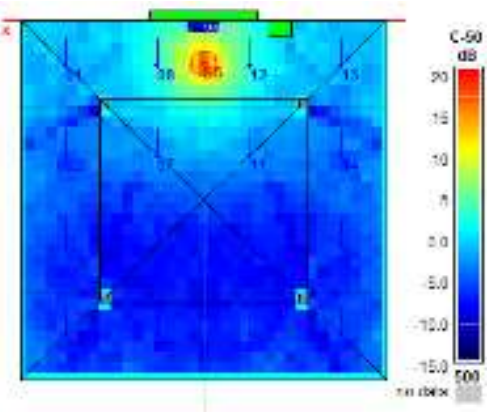

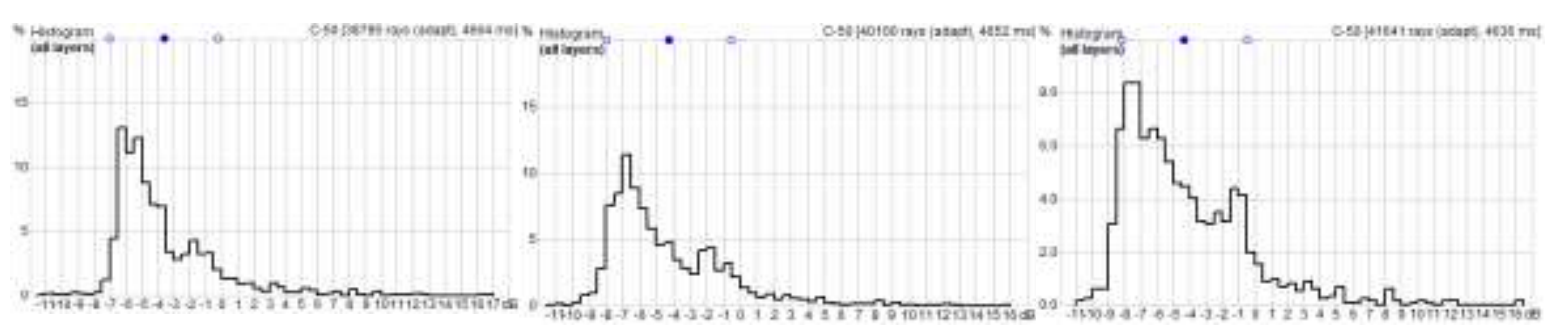

Figure 6. Mapping and histogram of clarity (C50) for:

(a) $\alpha=9^{\circ}$, (b) $\alpha=20^{\circ}$, and (c) $\alpha=31^{\circ}$.

\section{Ray Tracing}

In ray tracing analysis, a large number of sound rays are traced from the sound source point up to a high order of reflections following the optical law of reflection. The main result is the distribution of rays directing to the receiver location. This is analysed in appropriate intervals of the time delay, providing a qualitative representation of the sound distribution in space and time and is represented by a specular echogram graph. Early reflection indicated by the sound reflection arriving within $50 \mathrm{~ms}$ is useful as it enforces the direct sound arriving after the sound source has stopped (as the definition of C50). High energy of the early reflection will overcome the effect of reverberation. Difficulty achieving speech intelligibility comes when the reflection arrives after $50 \mathrm{~ms}$. Most of the reflections coming after that time blend with other reflections, creating echoes or undesired reverberation. Figure 7 shows the specular echogram until the second order of reflections for the corresponding pyramidal dome height. The results are shown for the receiver position located below the dome at position 6 (see Figures 5 and 6). It can be seen that an increasing number of reflections shift to the reverberant region, i.e. above $50 \mathrm{~ms}$, as the height of the dome increases. By comparing the same path for each reflection sequence, it is found that the sound reflection with the same sequence increases in time to reach the receiver as the angle of the dome increases. This is 
because the distance for the sound reflection to reach the receiver increases as the angle is increased, due to multiple reflections inside the dome.

(a)

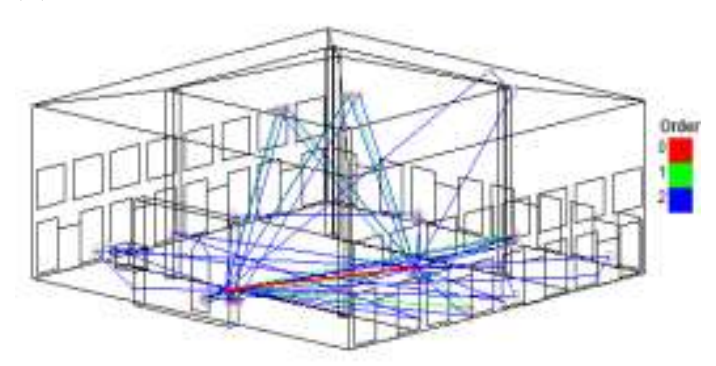

(b)

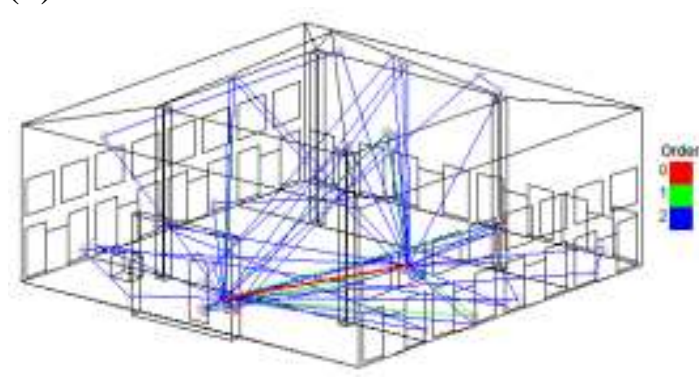

(c)

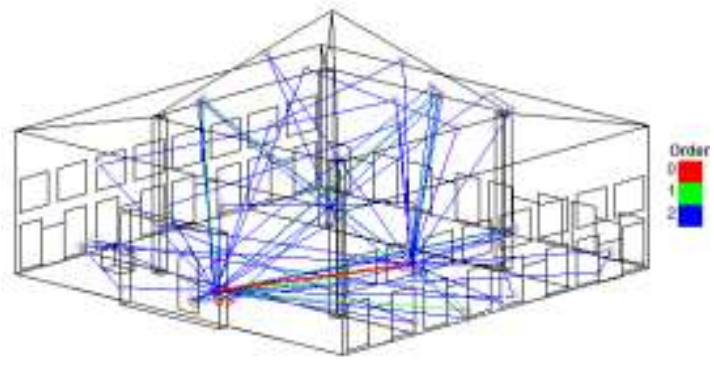

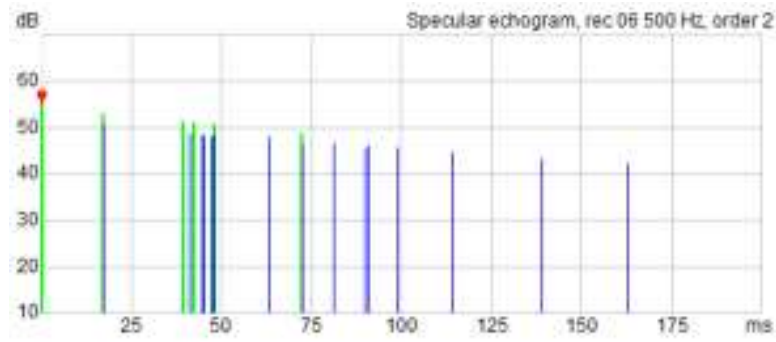
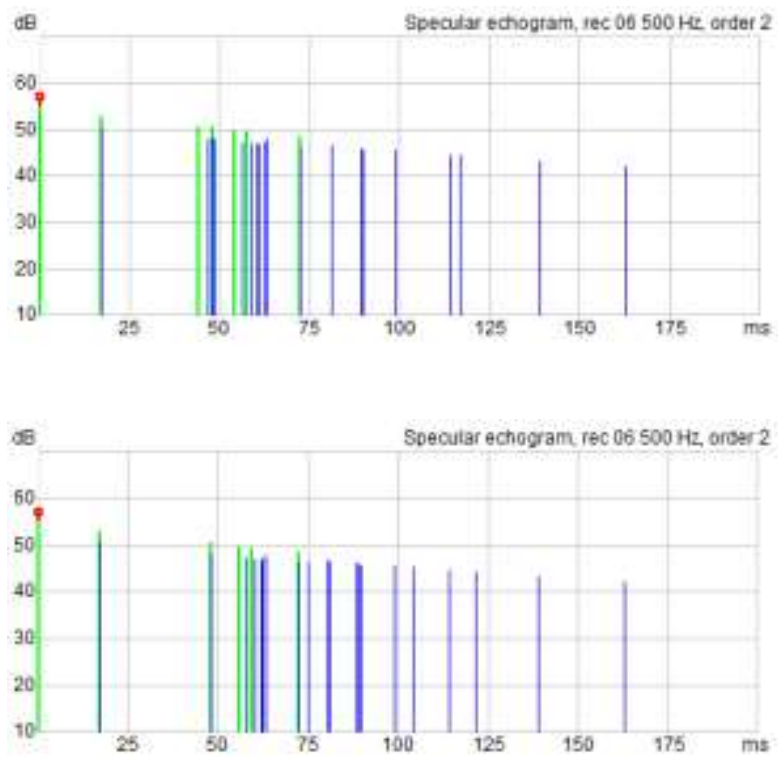

Figure 7. Ray tracing and specular echogram for: (a) $\alpha=9^{\circ}$, (b) $\alpha=20^{\circ}$, and (c) $\alpha=31^{\circ}$.

\section{CONCLUSIONS}

The effect of different angles of pyramidal dome on the acoustical characteristics in a mosque has been reported. The simulation results show that the lower or the smaller the angle of the pyramidal dome, the better the sound clarity in the mosque. This finding can be a useful input for architects when designing a dome for a mosque taking into account its effect on the interior acoustical performance. On the dome surface, acoustic materials or a Helmholtz resonator can be applied to absorb low frequency sound and to minimize the effect. The presence of carvings with calligraphy or Islamic geometric patterns may also help to distribute sound energy, although this is effective only at high frequency. It will also be of interest in future work to investigate other acoustical parameters, especially those representing the sound distribution in the mosque. This can then be compared with the typical spherical dome. 


\section{ACKNOWLEDGEMENTS}

This project is funded by a Short Term Research Grant from UniversitiTeknikal Malaysia Melaka (UTeM) No. PJP/2012/FKM(50C)/S01069.

\section{REFERENCES}

[1] Hammad RN. RASTI measurements in mosques in Amman, Jordan. Applied Acoustics. 1990;30:335-45.

[2] Abdelazeez MK, Hammad RN, Mustafa AA. Acoustics of King Abdullah Mosque. The Journal of the Acoustical Society of America. 1991;90:1441-5.

[3] Abdou AA. Measurement of acoustical characteristics of mosques in Saudi Arabia. The Journal of the Acoustical Society of America. 2003;113:1505-17.

[4] Weitze CA, Rindel JH, Christensen CL, Gade AC. The acoustical history of Hagia Sophia revived through Computer Simulation. Forum acusticum Sevilla 2002: 3rd European Congress on Acoustics Sevilla. 2002,16-20.

[5] Abdou AA. Comparison of the acoustical performance of mosque geometry using computer model studies. Eighth International IBPSA Conference. 2003.39-46.

[6] Sü Z, Yilmazer S. The acoustical characteristics of the Kocatepe Mosque in Ankara, Turkey. Architectural Science Review. 2008;51:21-30.

[7] Putra A, Hafizah D, Yaakob M, Nor M, Jailani M. Study on the Use of MicroPerforated Panel to Improve Acoustic Performance in Mosque. Applied Mechanics and Materials. 2013;393:971-5.

[8] Kayili M. Acoustic solutions in classic ottoman architecture. Foundation for Science Technology and Civilization. 2005:1-15.

[9] Soegijanto. Acoustical performance of Indonesian mosque. Acoustics of Worship Buildings, Proceedings of International Congress on Acoustics. 2001, 1-7.

[10] Prodi N, Marsilo M. On the effect of domed ceiling in worship spaces: A scale model study of a mosque. Building Acoustics. 2003;10:117-33.

[11] Setiyowati E. Strategies to increase the acoustical quality of the mosques without reinforcement system. Journal of Islamic Architecture. 2012;1:27-31.

[12] Long M. Architectural acoustics. USA: Elsevier; 2005.

[13] Bradley JS. Predictors of speech intelligibility in rooms. The Journal of the Acoustical Society of America. 1986;80:837-45.

[14] Bradley JS, Reich R, Norcross S. A just noticeable difference in $C_{50}$ for speech. Applied Acoustics. 1999;58:99-108. 